\title{
Love for Luxury, Preference for Counterfeits -A Qualitative Study in Counterfeit Luxury Consumption in China
}

\author{
Ling Jiang ${ }^{1} \&$ Veronique Cova ${ }^{2}$ \\ ${ }^{1}$ Faculty of Applied Economics, Aix-Marseille University, Aix en Provence, France \\ ${ }^{s}$ IAE Graduate School of Management, Aix-Marseille University, Aix en Provence, France \\ Correspondence: Ling Jiang, Faculty of Applied Economics, Aix-Marseille University, Aix en Provence, France. \\ Tel: 33-6-5283-4488. E-mail: ling.jiang@univ-amu.fr
}

\author{
Received: August 7, 2012 Accepted: August 20, 2012 Online Published: November 2, 2012 \\ doi:10.5539/ijms.v4n6p1 URL: http://dx.doi.org/10.5539/ijms.v4n6p1
}

\begin{abstract}
The aim of this study is to deepen the understanding of luxury counterfeit consumption by using the theories of luxury. This study is an interpretative qualitative research in which the social and personal meanings of luxury counterfeit consumption are explored. Both luxury and counterfeit provide a successful meaning transference. A good counterfeit can be regarded as the substitute good of luxury, which provides social meanings (conformity/status seeking/face saving), whereas it may also operate on a personal level (brand experience/fashion/adventure). The process of purchasing and consumption is fun and enjoyable due to the illegal nature of counterfeit. The research aspires to shed light on the essence of counterfeit in a brand perspective.
\end{abstract}

Keywords: counterfeiting, brands, consumer behavior, China

\section{Introduction}

How often do you see a dubious Louis Vuitton handbag or a pair of Prada sunglasses on sale in the street markets? The significant growth of luxury consumption over the past years has been accompanied with a dramatically rise of counterfeit. Consumer decisions to purchase fakes instead of originals have developed into a worldwide crisis. The counterfeit market is responsible for at least 200 billion dollars a year in lost jobs, taxes and sales (Furnham \& Valgeirsson, 2007). China has been acknowledged as the famous "made in" for counterfeit products, where all type of fake can be traced (Bian \& Veloutsou, 2007; Cheung \& Prendergast, 2006; Hung, 2003). These products lay over a vast range of goods including apparel electronics, foodstuff, pharmaceuticals, cosmetics products, and others. In particular, as the Chinese are avid consumers of luxury goods (Li \& Su, 2007; Sonmez \& Yang, 2005; Wong \& Ahuvia, 1998), the counterfeit of luxury brands has reached astronomical levels.

In a Confucian society context, Chinese consumers behave more irrationally in luxury purchase because luxury brands are something "must to have" for them to reinforce their social status. However, the wealth distribution is extremely unjust and the country has one of the largest gaps between the rich and the poor in the world according the statistics data from the World Bank. For most of them, the desire for luxury brands is not achieved due to the lack of affordability to exorbitant price tags of original luxury brands. Hence, the counterfeit manufacturer argue that their production are satisfying the demand of those consumers who unable or unwilling to pay for the originals (Lai \& Zaichkowsky, 1999). The consumer demand for counterfeit has raised substantial research. The attitude-intention behavior model has been vast studied. However, the explanations provided on the motivation of luxury counterfeit and the association between original luxury and counterfeit luxury consumption are still missing.

Given that the market for counterfeit luxury brands relies on consumers' desire for real luxury brands(Hoe, 2003; Penz \& Stöttinger, 2005), it is critical for researchers to study the reasons why consumers purchase the fake brand from their perception of real brand, and whether their perception of luxury brand will affects their counterfeit consumption. This is where our paper focuses: based on twenty-fives interviews with the luxury counterfeit consumers, we provide to study the counterfeit consumption into a brand perspective. We aim to explore the brand interpersonal and personal effect in the counterfeit luxury brand consumption, to better understand the reason why consumers buy and own fakes. As such, we contribute to define a set of key drivers of 
interpersonal and personal meanings in counterfeit products. The connection of luxury brand and counterfeit luxury brand will be highlighted that help to reduce the complexity of counterfeit consumption and enrich the literature.

\section{Literature Review}

\subsection{Counterfeit Definition}

Generally the brand of an enterprise is its most valuable asset. But the success of a brand may cause counterfeiting (Maldonado \& Hume, 2005). The history of counterfeit brands of luxury products goes back to A.D. 27. In that period, the wine Merchant Gaul filled wine bottle with cheap local wine and sold them as expensive Roman wines. Around 19th century, the counterfeits of valuable trademarks became wider and counterfeiting became a crime that requires punishment in some European countries) (Wilcox, Kim, \& Sen, 2009).

As with any topic, there are various interpretations of the basic concept for the area of counterfeiting study. Kay (1990)'s defined counterfeiting as the production of copies that are identically packaged, including trademarks and labeling, so as to seem to a consumer that the item is the genuine article. Bloch, Bush, and Campbell (1993) defined counterfeiting as the unauthorized copying of trademarked or copyrighted goods. In the work of Cordell, Wongtada, and Kieschnick (1996), the product counterfeiting is defined as any manufacturing of goods whose special characteristics are protected as intellectual property rights. Eisend and Schuchert-Culer (2006) viewed counterfeiting as meaning that an original product with a remarkable brand value worth copying already existed on the market; the product attributes were copied into another product, which was indistinguishable from the original, and was sold at a lower price as if it were the original. For this study, the definition of Eisend and Schuchert-Culer was used because this definition highlights the key component of a luxury counterfeit: that the characteristics of copied product are identical to the genuine and the original brand value is involved.

From the consumer's perspective, the literature has identified two forms of counterfeiting, as deceptive and non-deceptive. Under deceptive counterfeiting, the consumer is a victim of deception, they are not aware of purchasing a fake product. In our study, we specifically focus on non-deceptive counterfeit product, where consumers intentionally purchase fake products (Grossman \& Shapiro, 1988). This form of counterfeiting is more commonplace in luxury brand markets (Nia \& Zaichkowsky, 2000), where consumers are often able to distinguish counterfeits from genuine brands based on differences in price, the distribution channels, and the inferior quality of the product itself.

\subsection{Consumer Demand for Luxury Brand Counterfeit}

Previous research has developed many factors to understand the phenomenon of counterfeits activities. It is commonly agreed that the consumers' demand for counterfeits is one of the major reason of the existence of the counterfeiting phenomenon. So a number of researches have called for investigation in consumer demand behavior of counterfeiting study, in particular, the determinants of CBP purchase intention. We classify here the determinants into five categories:

The first category based on characteristics of the product, such as price, investment risk (e.g. Cordell et al., 1996), product type (e.g. Albers-Miller, 1999), product attribute variables, and style/fashionability (e.g. Bloch et al., 1993). Obviously, the price difference is the best advantage of the counterfeit product, those consumers buy counterfeits because they are getting prestige without paying for it (Bloch et al., 1993; Albers-Millier, 1999; Harvey and Walls, 2003); The second category includes consumers' demographic and psychographic variables, as well as consumer's attitudes toward counterfeiting. For example, previous studies have found that consumers who purchase counterfeit products are usually have a lower social status (e.g. Bloch et al., 1993; Wee et al., 1995) and have more favorable attitudes toward counterfeiting (e.g. Penz and Stottinger, 2005); The third category refers to the social and cultural context in which the counterfeit purchase decision is made from cultural norms (Lai and Zaichkowsky 1999), there is a significant relationship between the country of origin, consumers' ethnocentrism and consumers' perceived risk when buying a counterfeit (Chakraborty, Allred, \& Bristol, 1996). Likewise, the social functions served by consumers' luxury brand attitudes can influenced the demand for counterfeit. (Wilcox et al., 2009); The fourth category refers to the mood and situational context. For example, consumers are likely to purchase a counterfeit brand when they are abroad or on holiday. The tourist consumers are more likely to purchase the counterfeits products as an authentic experience (e.g. Gentry \& al., 2001); The fifth category refers to the consumers' ethical and lawfulness cues. For some, they holding lax attitude about the legal protection of intellectual property (e.g. Tom et al., 1998). The consumers who are more lawful-minded are less willing to buy counterfeit. In contrast, those who have lower ethical standards are less feel accountable for a counterfeit buying behavior (e.g. Cordell et al., 1996). 


\subsection{Luxury Brand and Counterfeit Luxury Brand Relevance}

Among the many product categories that could be counterfeited, one of the most counterfeited products is luxury item(Grossman \& Shapiro, 1988). The brand is always associated with the counterfeiting, because a counterfeited luxury brand must copy an existed famous trademarked brand(Cordell, Kieschnick, \& Wongtada, 1996); meanwhile, a successful brand should have the highest attractiveness level to counterfeiters. In fact, according to a website statistic, the most desirable brands for Chinese consumers are LV, Gucci and Burberry. The trademark Louis Vuitton turn into the primary target of counterfeiters, which can be abundantly found in street markets, small shops, flea markets, and through web selling.

In the context of non-deceptive counterfeiting, several previous studies proposed if consumers don't attracted by brand product, counterfeited brand product will not be an issue (Bloch, Bush, \& Campbell, 1993; Cordell et al., 1996). Few studies argued that the decision to buy a counterfeit product not only represents a product choice decision, but also represents a brand decision (Eisend \& Schuchert-Güler, 2006; Gentry, 2006). Since the quality of counterfeit products has been steadily improving over the years, some counterfeits are recognized as the same quality, same design and even better durability than the originals. Turunen and Laaksonen (2011) indicate that the perceived authenticity of luxury product is the major difference to counterfeit product. The counterfeit is regarded as the pursuit of luxury by imitating its attributes, but it is can be also placed on the brand level. Since it is debated that luxuries are divided into different level depend on the context and the people concerned, a counterfeit brand can be regarded as the lowest level of luxury, and the consumers may profit the "look-alike" brand instead of the original one as the props aiding them to get desired benefits.

From this point of view, it is necessary to link up the luxury consumption value and counterfeit luxury consumption. (Vigneron \& Lester, 1999) argue that luxury brand items contain both interpersonal and personal meanings. This interpersonally oriented motivation is much more externally driven and represents the consumers' desire to impress others. The personal orientation such as hedonism and materialism are internally driven and reflect the self-fulfillment goals. Hence, we propose in this study to understand the counterpart of luxury brand from interpersonal and personal aspect:

- We suggest that consumption of luxury brands' counterfeits may result in the construction of a positive image for the social needs.

- We suggest that the experience of consuming luxury products' counterfeits may be motivated by self-need or self-pleasure.

\section{Methodology}

The empirical part of this study aims to identify what kind of meanings contained by counterfeit luxury brand. To carry out this research, we opted for a qualitative research design. A total of twenty-five in-depth interviews were collected. The participants were selected based on experience with fake luxury brands. They came from four Chinese first tier cities (Beijing, Shanghai, Guangzhou and Wuhan), where the exclusive stores selling international luxury brands are found and the counterfeits can be abundantly found in street markets, small shops, flea markets, and through web selling. $60 \%$ of participants were female, $40 \%$ male; about half of the respondents were younger than 28 years, the other half older. The younger participants were college students or recently graduated professionals. Most of the older participants were married and had children; they were business people or employees. All the participants had considerable disposable incomes and were interested in luxury and counterfeit brand. The participants' data is presented in Table 1.

Table 1. Profiles of participants in the study

\begin{tabular}{llllll}
\hline Number & Name & Gender & Age & City & Occupation \\
\hline 1 & Zixi & Female & 24 & Shanghai & College student \\
2 & Juan & Female & 28 & Shanghai & Professor \\
3 & Xian & Female & 25 & Shanghai & Professor \\
4 & Fang & Male & 34 & Shanghai & Engineer \\
5 & Zhihui & Male & 35 & Shanghai & Manager \\
6 & Helene & Female & 32 & Beijing & Accounting \\
7 & Hu & Male & 40 & Beijing & Manager \\
8 & Liang & Male & 26 & Beijing & Salesman \\
9 & Lisa & Female & 20 & Beijing & College student \\
10 & Yi & Female & 49 & Wuhan & Interpreter \\
11 & Susu & Female & 39 & Wuhan & Professor \\
\hline
\end{tabular}




\begin{tabular}{llllll}
\hline 12 & Jojo & Female & 19 & Wuhan & College student \\
13 & Feng & Male & 29 & Wuhan & Engineer \\
14 & Bo & Male & 26 & Wuhan & Salesman \\
15 & Yingni & Female & 35 & Wuhan & Accounting \\
16 & Xiao e & Female & 25 & Guangzhou & College student \\
17 & Yajing & Female & 30 & Guangzhou & Public functionary \\
18 & Candy & Female & 23 & Guangzhou & Office clerk \\
19 & Sky & Female & 28 & Guangzhou & Business supervisor \\
20 & Cherry & Female & 27 & Guangzhou & Salesman \\
21 & Pheobe & Female & 38 & Guangzhou & Salesman \\
22 & Huan & Male & 24 & Guangzhou & Photographer \\
23 & Paul & Male & 40 & Guangzhou & Manager \\
24 & Ming & Male & 45 & Guangzhou & E-business engineer \\
25 & Yuan & Male & 33 & Guangzhou & Stage director \\
\hline
\end{tabular}

Since the topic is sensitive, we assured the participants that their anonymity would be preserved. In the interviews, we began with several demographic questions to warm up, and then explored respondents' general views towards luxury product and finally talk about counterfeits' consumption. The counterfeit interpreted especially as counterpart of luxury brand. We asked for the beliefs, feelings, expectations and reasons present during the processes of consuming the products, and let the participants describe their recent consumption experience of luxury brand counterfeit product. The product attributes and shopping context described by the respondents can reflect the interpersonal and personal meanings about the product. Each interview lasted between 30 and 70 minutes. All interviews were conducted in Chinese and recorded, transcribed, then translated into English by a professional linguister in Rhewin Translation at the city of Beijing. For the analysis, we categorized the data by the thematic content analysis, and then developed comparisons between the coded reports of the software tool NVivo9 in order to identify the emerging themes.

\section{Results: Emerging Themes in Consumption of Counterfeit Luxury Goods}

In the following, we present the results along two dimensions that emerged from the key topics discussed in the focus groups. The first dimension refers to interpersonal aspect of consumption of counterfeit luxury goods related to conformity, status seeking and face consciousness; the second dimension rests on personal aspect related to fashion consciousness, brand experience and adventure. We shall now analyze each theme in detail.

\subsection{Interpersonal Aspect}

\subsubsection{Conformity}

Social conformity was defined as "the change in their product evaluations, attitude, purchase intentions, or purchase behavior as a result of exposure to the evaluations, intentions, or purchase behaviors of referent others" (Lascu \& Zinkhan, 1999). According to Lascu and Zinkhan, conformity plays an important role in shaping individuals' decisions toward product choices based on the influence of referent others.

Be part of the Confucianism, the conformist is one of the most important social factors, influencing the individual and social behavior in China. The Chinese culture has traditionally intensified the level of social behavior over the personal, and therefore strengthened the social influence on individual behavior. In the field of consumption, Chinese consumers are very sensitive to attention and the reaction of others.

“...Now you can go down to the Nanjing Road (one famous walking road in Shanghai), all type of ladies, high, thin, fat, or short...they are wearing a LV or at least a Coach. How can I walk between them without a brand bag..."(Female, Xian)

"...Especially to those friends having a lot of money, I won't tell them that the products is a fake. They might mock at me..." (Male, Yuan)

Our respondents normally prefer a product that is widely used by their social group than a product they ever sees. They do not want to be too backward to their social group, because the strong social risk of "losing face". This shows that Chinese consumers are more interested in the social necessity of luxury than a necessity itself. This also means that consumers are not simply searching for branded products, but also for further "products" within the luxury brand model. More precisely, our respondents make a brand choice since they want to be similar to their peers or social groups. However, after the brand decision, consumers now faced with another choice, whether to purchase a genuine item or a counterfeit. As a result of financial reason, they could no longer afford the brand, but could offer a counterfeit version in order to auto-classify themselves as one of the luxury brand 
users and be able to conform to their social groups.

"Without a brand, nobody looks you in the street." (Female, Xian)

\subsubsection{Conspicuousness}

According to Goldsmith, Flynn, and Eastman (Goldsmith, Eastman, Calvert, \& Flynn, 1996), status consumption is defined as the "motivational process by which individuals strive to improve their social standing through the conspicuous consumption of consumer products that confer and symbolize status both for the individual and surrounding significant others". Status-consumption consumers, regardless of their current class ranking, may desire products, which are indicators of a higher social status (Goldsmith et al., 1996).

For the respondents in this study, the luxury brand itself was the main reason for purchase and the meaning associated with the original brand that can be transferred to the users. Individuals seek status to obtain a position or rank given by others in the society. However, Veblen (1899) argument that consumers' desire to gain status is enhanced by conspicuous products indicated that consumers may not always spend higher prices for goods in order to achieve status; they may also purchase a larger quantity of conspicuous goods at lower prices in order to gain esteem. This indicates that consumers may obtain status from consumption of non-expensive products as well. The luxury brands sold at an exorbitant price, which is not affordable for some consumers. This contributes to a dissonance whereby consumer resort to a look-alike luxury brands to satisfy their status seeking needs.

"Here people get impressed if you are wearing an expensive brand...although you know it's a counterfeit." (Male, Paul)

Chinese consumers even behave more irrationally in luxury purchase because luxury brands are something "must to have" for them to reinforce their social status. However, with lower-price acceptability, our respondents have to try a low-grade version with the intent of purchasing the genius item if the trial is successful.

"It was a Hugo boss suit and it had the brand label on the sleeve. My girl friend bought it for me, because I was going to a conference and I have to get well dressed. I thought 'I will look smart in it', the brand was there and it distracts people from looking at me." (Male, Zhihui)

Thus, this study considers that the consumers of counterfeiting luxury brand are indeed seeking a higher social status. They take a lower cost to satisfy their social-status needs.

\subsubsection{Face Saving}

Face refers to a sense of favorable social self-image that a person wants others to obtain in a relational and network context. It contributes to people's socially defined aspect of self, which is usually considered as tightly related to Chinese culture (Chan et al., 2009; Yau, 1988). Maintaining face is regarded as an important goal in social interactions (White et al., 2004).

"There are many who are willing to spend one-month salary to buy something, not for quality, not for taste, but only for one thing: face." (Female, Xian)

Prior research in consumer behavior shows that face pressure represents an important driver of luxury consumption in China (Wong \& Ahuvia, 1998). Well, price-insensitive consumers or consumers without financial capacity are always attracted by copies of luxury. With de development of online shopping, Chinese consumers seem to have discovered a new creative way for face saving:

"You can even find paper bags of LV or Chanel sold online. I mean the package of such top brand goods." (Female, Susu)

People who cannot afford luxury brand products are buying paper bags with high-end brand names or logos to gratify their vanity. Some are even finding luxury labels, instruction books and receipts sold online. All of these are regarded as the most economic way to get "luxury" goods. Now we can find all the accessories of luxuries of all the brands from Hermes to Prada on Internet. In the shopping page, we found one of the buyer gave a 5 stars satisfaction to the seller and leave a message:

"The paper bag made me in relation with the brand." (Female, from one of the buyer in Tmall)

Several respondents mentioned the online shopping Tmall during the interviews. With professional search engine, hundreds of thousands of counterfeit merchandisers are providing low prices, faster delivery times and wider range of delivery for consumers demand. One example, by publishing only 15 days, the selling page attained 290 deal records for one Louis Vuitton handbag. This is only a data of one objet offered by one seller. From the page feedback history, the consumers exchanged their opinions. The degree of satisfaction depends on the degree of similarity. They are happy to gain social image at a much lower cost. However, we discovered not anyone who 
purchased have made evaluation for the product. A great number of consumers choose anonymous buying, and the evaluation is made by system default. This may explained by one of our respondents:

"In our company, she always wears high-end brand, and never shall the shopping experience with us. On one occasion, I accidently see her web favorite was full of Tmall shops. Well, in fact she's also a big fake fan..." (Female, Pheobe)

Saving face in public boost consumers without financial capacity to buy and use counterfeits of well-known luxury brands. However, the great social risk of losing face occurred if others find out that they use counterfeits. Therefore, the face consciousness represents as a double-edged sword for consumers of counterfeits.

\subsection{Personal Aspect}

\subsubsection{Fashion Consciousness}

Nam \& al., (2007) defined fashion consciousness as "a person's degree of involvement with the styles of fashion products" (p. 103). Researchers have further referred to fashion-conscious consumers as those individuals who are characterized by a deeper interest in fashion brands and products as well as in their physical appearance (Gutman \& Mills, 1982; Summers, 1970). As the appearance and visibility are particularly sold for fashion items, and the majority respondents felt that the visual brand cue is important rather than any intrinsic feature of the item itself. We propose that a fashion component is important than the functional importance for those consumers of counterfeiting luxury brands.

"I think it is okay, I know is a fake but it's the same style." (Male, Liang)

"The appearance is important when I selected a handbag." (Female, Zixi)

"I bought it because I liked the style and the design and it was not because of the brand." (Male, Hu)

The consumer today can enjoy the same lifestyle at a lower price through a counterfeited version of highfashion luxury product. With a dynamic progress of technology, some counterfeits became as real as possible to the genius. Consumers of counterfeit luxury goods do not view low quality negatively, but pay great positive attention to the appearance of the copycat.

"I'm searching for the model." (Female, Xiao e)

The fashion item is always relative with a short product life cycle, they have to go out of fashion after a certain period, and most people are generally unwilling to spend an exorbitant amount of money on them. Our respondents argument how rational they are, and the cheaper copy is a smart choice, cause the money they save can invest to a new counterfeit version at the next season. Consumers were inclined to purchase a much cheaper counterfeit version of expensive luxury brands to stay up to date and show their tastes.

"You could never keep the same speed with the fashion. I buy a new jacket today, it will be old-fashioned next autumn, and I should buy another new jacket with the a little improve of its cuff for example. But this tiny change is changed in our eyes." (Female, Yingni)

"I have an original Louis Vuitton handbag; it's the classic style that will never go out of fashion. But if it's a trendy one, a new collection, I'll choose the fake one." (Female, Pheobe)

\subsubsection{Brand Experience}

The literature conceptualized brand experience as sensations, feelings, cognitions, and behavioral responses evoked by brand-related stimuli (Brankus, 2009). This means brand experience include the psychological and internal consumer reactions. The hedonic dimension of luxury brand could provide the subjective emotional benefit such as sensory gratification and inner pleasure. A counterfeited luxury one may fail to provide such experience due to the low quality associated. But our respondents emphasized that they can obtain really good counterfeits.

"There are many authorized factory in China, we all know that these branded thing were made in china. We can easily find a super well made fake." (Female, Candy)

"I've heard of someone in the province of Zhejiang. He produces the counterfeit level AAA that the copy was promised as possible as the same of the genuine article. I think he just knows the manager or someone in the authorized brand factory, and they gave him some important raw and processed materials." (Male, Ming)

When two products look alike, such as the counterfeit brand and its real version, they are often perceived as being similar (Shocker, Bayus, \& Kim, 2004).Respondents assumed that luxury brand counterfeit offers a superior quality than non-luxury brand. We found a lot of them know well the originals brands through different 
channel. Since the exorbitant price hinder their purchase decision, they carefully chose counterfeits version to project a desired brand experience, and the usage of a good counterfeit brand can increase their knowledge of the originals.

"I know the original brand. It costs too expensive and I resort to a copy one." (Female, Lisa)

"I wish I could have the real one, but I'm also happy when I wear it (counterfeit version)." (Female, Susu)

Our interviews show the consumers satisfied if the fake was similar to the real version. That indicates the luxury counterfeit version could also contribute to consumer's hedonic needs. For this type of consumer, a super well made counterfeited one can provide a similar brand experience but has been bought at an incredibly lower price.

\subsubsection{Adventure}

Hirschman and Holbrook (Hirschman, 1982) defined hedonic consumption as those facets of consumer behavior that relate to the multisensory, fantasy and emotive aspects of product usage experience. We found the majority respondents smiled and some even laughed during the interview. They are willing to talk about their counterfeit experience, and the ton is fulfilled with enjoyment.

"With my girlfriends, we love to discuss the model, compare the quality and the copy level. If someone finds a new store that selling good version, we'll go to look for it together. That's totally fun!" (Female, Susu)

Not only the funny emotion was expressed during the interview, the participants also described a type of nervous and excited feeling. Their experiences turned to like great stories:

"You know the Qipuroad? If you go shopping there, some stranger will pass by you and whispered 'do you want to buy bags?' Then he will lead you to a store where the sliding wall is closed. After we entered, we saw all the stuff, different models of Gucci, Louis Vuitton, and Channel ...that's fantastic! But I do feel nervous, especially when he put the sliding wall closed!" (Female, Cherry)

Obviously, there are emotions of pleasure and enjoyment related to the counterfeit consumption experience. But we chose to nominate this theme as "adventure" because the fear of being recognized using a fake also exist during the processes. One of our respondents - Cherry's sense of nervous seemed to due to the illegal aspect of counterfeit experience. Generally, the participant are willing to describe their experience of counterfeit brand because they already achieving the positive benefit or emotion from this type of activities. The enjoyment occurs only when the copy is not discovered. On the one hand, they are having fun with the counterfeits; on the other hand, they feel nervous if the copy is exposed by others.

"I have originals and also fakes. One day when I shopping with my friend, he asked me to test the brand salesman that if he can recognize the real and fake. I said the zipper puller is broken and showed him my fake. You know what? He just didn't discover it!" (Female, Sky)

Thus, just because of this illegal and social tension aspect, the counterfeit contribute to produce endless fun for those consumers.

\section{Discussions, Limitations and Future Research}

Arellano (Arellano, 1994) states that the exchange of counterfeit products doses not aim to deceive consumers, but to satisfy them. This exploratory study analyses the various ways that consumer draw the external and internal meaning from the consumption of counterfeit luxury brand product. The respondents attained not only the social image that counterfeits help them to make, but also a psychological benefit and value through consumption.

From the interpersonal aspect, the luxury brand's meaning and signaling effect is created through the same product design by the fake versions. The counterpart must represent as real as possible to the originals for a successful meaning transference. A necessity of being similar with the social group and a wish to get status pushed consumers seek for luxury brands. The reason why consumers resort to counterfeits due to the unwilling or unable to pay for the real. Hence, the counterfeit is depending on the existence of the luxury itself. In this context, the "loud luxury", which logo that are visible recognizable are more common place in counterfeit, because the logo interpret meaning and manifest the desired status for the users. If counterfeit don't appear the same design as the originals, if the consumers don't use them in the creation of their identities and the fulfillment of social needs, there would be no consequent market for counterfeit.

The importance of interpersonal issues requires the counterfeit represent as similar as the real. The nature of counterfeit activities depends on the need or desire for the real brand. However, the value consumers draw from a counterfeit as personal meanings is much more linked to the essence of illegal product itself. Compared to 
original luxury brand, counterfeit luxury brand product represent as more reasonable and more customer-oriented. The personal oriented consumers have a low need to display social status, but manifest much more a self-interest orientation. The process of purchasing and consumption is fun and enjoyable, a much cheaper counterfeit represent a smart choice that made additional happiness for consumers.

This study contributes to understand the consumption of luxury counterfeits by establish luxury concept as an antecedent. The correlation between counterfeit and luxury product demonstrate the importance of social issues and the obtainment of personal gratification. The limitations based on the sample size, which was not large enough to draw strong conclusion. As our respondents are extremely price conscious, an investigation with the consumers of high socio-economic identity might get different result. It would be also interesting to investigate the social risk of being "caught" wearing copycat product for future research.

\section{References}

Albers-Miller, N. D. (1999), Consumer misbehavior: why people buy illicit goods. Journal of Consumer Marketing, 16(3), 273-87. http://dx.doi.org/10.1108/07363769910271504

Arellano, R. (1994). Informal-underground retailers in less-developed countries: An exploratory research from a marketing point of view. Journal of Macromarketing, 14(2), 21-21. http://dx.doi.org/10.1177/027614679401400203

Bian, X., \& Veloutsou, C. (2007). Consumers' attitudes regarding non-deceptive counterfeit brands in the UK and China. [Article]. Journal of Brand Management, 14(3), 211-222. http://dx.doi.org/10.1057/palgrave.bm.2550046

Bloch, P. H., Bush, R. F., \& Campbell, L. (1993). Consumer accomplices's in product counterfeiting: a demand-side investigation. Journal of Consumer Marketing, 10(2), 27-36. http://dx.doi.org/10.1108/07363769310047374

Brankus, J. J., Schmitt, B. H., \& Zarantonello, L. (2009). Brand experience: What is it? How is it measured? Dose it affect loyalty? Journal of Marketing, 73(May), 52-68. http://dx.doi.org/10.1509/jmkg.73.3.52

Chakraborty, G., Allred, A., \& Bristol, T. (1996). Exploring consumers evaluations of counterfeits the roles of country of origin and ethnocentrism. Advances in Consumer Research, 23, 379-384.

Chan, H., Wan, L. C., \& Sin, L. Y. M. (2009). The constrasting effects of culture on consumer tolerance: Interpersonal face and impersonal fate. Journal of Consumer Research, 36(2), 292-304. http://dx.doi.org/10.1086/597329

Cheung, W.-L., \& Prendergast, G. (2006). Buyers' perceptions of pirated products in China. Marketing Intelligence \& Planning, 24(5), 446-462. http://dx.doi.org/10.1108/02634500610682854

Cordell, V. V., Kieschnick, R. L., Jr., \& Wongtada, N. (1996). Counterfeit purchase intentions: role of lawfulness attitudes and product traits as determinants. Journal of Business Research, 35(1), 41-41. http://dx.doi.org/10.1016/0148-2963(95)00009-7

Eisend, M., \& Schuchert-Güler, P. (2006). Explaining Counterfeit Purchases: A Review and Preview. Academy of Marketing Science Review, 2006, 1-1.

Furnham, A., \& Valgeirsson, H. (2007). The effect of life values and materialism on buying counterfeit products. The Journal of Socio-Economics, 36(5), 677-685. http://dx.doi.org/10.1016/j.socec.2007.01.004

Gentry, J. W. P. S. I. I. C. J. (2006). The effects of counterfeiting on consumer search. Journal of Consumer Behaviour, 5(3), 245-256. http://dx.doi.org/10.1002/cb.176

Goldsmith, R. E., Eastman, J. K., Calvert, S., \& Flynn, L. R. (1996). Status consumption and self-image: A replication with Mexican consumers. Association of Marketing Theory and Practice Proceedings, 317-323.

Grossman, G. M., \& Shapiro, C. (1988). Foreign Counterfeiting of Status Goods. The Quarterly Journal of Economics, 103(1), 79-79. http://dx.doi.org/10.2307/1882643

Gutman, J., \& Mills, M. K. (1982). Fashion Life Style, Self-Concept, Shopping Orientation, and Store Patronage: An Integrative Analysis. Journal of Retailing, 58(2), 64-64.

Harvey, P. J., \& Walls, D. (2003), Laboratory markets in counterfeit goods: Hong Kong. Applied Economic Letters, 10(14), 883-887. http://dx.doi.org/10.1080/1350485032000155431

Hirschman, E. C. (1982). Hedonic Consumption: Emerging Concepts, Methods and Propositions. Journal of Marketing (pre-1986), 46(000003), 92-92. 
Hoe, L., Gillian Hogg \& Susan Hart. (2003). Fakin'It : Counterfeiting and Consumer Contradictions. European Advances in Consumer Research, 6, 60-67.

Hung, C. L. (2003). The Business of Product Counterfeiting in China and the Post-WTO Membership $\begin{array}{lllll}\text { Environment. Asia Pacific Business } & \text { Review, } & 10(1), & \text { 58-77. }\end{array}$ http://dx.doi.org/10.1080/13602380412331288810

Kay, H. (1990). Fake's progress, Management Today, July, 54-8.

Lai, K. K.-Y., \& Zaichkowsky, J. L. (1999). Brand imitation: Do the Chinese have different views? Asia Pacific Journal of Management, 16, 179-192. http://dx.doi.org/10.1023/A:1015482707900

Lascu, D.-N., \& Zinkhan, G. (1999). Consumer conformity: Review and applications for marketing theory and practice. Journal of Marketing Theory and Practice, 7(3), 1-12.

Li, J. J., \& Su, C. (2007). How face influences consumption: a comparative study of American and Chinese consumers. International Journal of Market Research, 49(2), 237-250.

Maldonado, C., \& Hume, E. C. (2005). Atitude toward counterfeit products: an ethical perspective. Journal of Legal, Ethical and Regulatory Issues, 8(1/2), 105-117.

Nam, J., Hamlin, R., Hae Jin, G., Kang, J. H., Kim, J., Kumphai, P., \& Richards, L. (2007). The fashion-conscious behaviours of mature female consumers. International Journal of Consumer Studies, 31(1), 102-108. http://dx.doi.org/10.1111/j.1470-6431.2006.00497.x

Nia, A., \& Zaichkowsky, J. L. (2000). Do counterfeits devalue the ownership of luxury brands? Journal of Product \& Brand Management, 9(7), 485-497. http://dx.doi.org/10.1108/10610420010351402

Penz, E., \& Stöttinger, B. (2005). Forget the "Real" Thing-Take the Copy! An Explanatory Model for the Volitional Purchase of Counterfeit Products. Advances in Consumer Research, 32(1), 568-575.

Shocker, A. D., Bayus, B. L., \& Kim, N. (2004). Product Complements and Substitutes in the Real World: The Relevance of "Other Products". Journal of Marketing, 68(1), 28-40. http://dx.doi.org/10.1509/jmkg.68.1.28.24032

Sonmez, M., \& Yang, D. (2005). Manchester United versus China: A counterfeiting and trademark match. Managing Leisure, 10(1), 1-18. http://dx.doi.org/10.1080/13606710500086611

Summers, J. G. (1970). The identity of women's clothing fashion opinion leaders. Journal of Marketing Research, 7(May), 178-185. http://dx.doi.org/10.2307/3150106

Turunen, L. L. M., \& Laaksonen, P. (2011). Diffusing the boundaries between luxury and counterfeits. The Journal of Product and Brand Management, 20(6), 468-474. http://dx.doi.org/10.1108/10610421111166612

Veblen, T. B. (1899). The Theory of the Leisure Class. Boston.

Vigneron, F., \& Lester, W. J. (1999). A Review and a Conceptual Framework of Prestige-Seeking Consumer Behavior. Academy of Marketing Science Review, 1999, 1-1.

Wee, C. H., Tan, S. J., \& Cheok, K. H. (1995), Non-price determinants of intention to purchase counterfeit goods: an exploratory study, International Marketing Review, 12(6), 19-46. http://dx.doi.org/10.1108/02651339510102949

White, J. B., Tynan, R., Galinsky, A. D., \& Thompson, L. (2004). Face threat sensitivity in negotiation: Roadblock to agreement and joint again. Organizational Behavior and Human Decision Processes, 94(2), 102-124. http://dx.doi.org/10.1016/j.obhdp.2004.03.005

Wilcox, K., Kim, H. M., \& Sen, S. (2009). Why Do Consumers Buy Counterfeit Luxury Brands? Journal of Marketing Research (JMR), 46(2), 247-259. http://dx.doi.org/10.1509/jmkr.46.2.247

Wong, N. Y., \& Ahuvia, A. C. (1998). Personal Taste and Family Face: Luxury Consumption in Confucian and $\begin{array}{lllll}\text { Western Societies. Psychology \& } \quad \text { Marketing, } & \text { 15(5), }\end{array}$ http://dx.doi.org/10.1002/(SICI)1520-6793(199808)15:5<423::AID-MAR2>3.0.CO;2-9

Yau, O. H. M. (1988). Chinese cultural values: Their dimensions and marketing implications. European. Journal of Marketing, 22(5), 44-57. http://dx.doi.org/10.1108/EUM0000000005285 